\title{
Review of Carsten Herrmann-Pillath's Foundations of economic evolution: a treatise on the natural philosophy of economics. Edward Elgar, 2013, 704 pp.
}

\author{
DON Ross \\ University of Cape Town \\ Georgia State University
}

There is no settled view among economists about the place of their discipline in the general architecture of the sciences, but in their methodological remarks one finds two common ways of side-stepping the issue. Some, for example Edward Leamer (2012), maintain that economics is not a science, but is rather a craft aimed at policy engineering. Leamer directs his criticisms against a more traditional alternative, which defends the scientific credentials of economics, and at the same time distinguishes economics from other sciences, by reference to applications and extensions ${ }^{1}$ of a set of axioms descended from Paul Samuelson (1947). The discipline's most influential textbooks (such as Mas-Colell, et al. 1995), present economics according to the latter approach, which finds its logical apotheosis in the work of Bernt Stigum (1990). In this context it is straightforward to identify relationships between economics and similarly axiomatized domains of inquiry, such as the psychology of decision making, by comparing axiom sets. I refer to this philosophy as a way of avoiding substantive questions about interdisciplinary relationships because it displaces them by purely technical ones and, more importantly, because it renders by fiat all questions about the place of economics among those sciences that are not axiomatically structured implicitly ill-formed and therefore unanswerable. This point applies to the majority of behavioral and social sciences.

Since the demise of logical empiricism, few philosophers of science have supported the idea that the boundaries of empirical sciences can be literally identified with formal structures. This does not force us over to Leamer's view, because the dichotomy he assumes is too restrictive. It is possible to agree with him that economists are and should be

\footnotetext{
${ }^{1}$ The most important extensions to which I allude are game theory, expected utility theory, and general equilibrium theory.
} 
practical in their focus and opportunistic in their use of sources of evidence, while nevertheless believing that economists have managed to collectively discover some theoretical generalizations about the structure of the social world. That is enough to motivate interest in how these generalizations can be true of the same world as claims in apparent tension with them that emerge from related disciplines such as sociology (Coleman 1990), demography (Clark 2009), cognitive science (Simon 1957; Clark 1997; Ross 2005; Kahneman 2011), neuroscience (Glimcher 2012), evolutionary psychology (Ofek 2001), the psychology of motivation and personality development (Schelling 1978, 1980; Ainslie 1992, 2001), ethology (Noë, et al. 2001), and the histories of technology (Ziman 2000; Brynjolfsson and McAfee 2012), business (Schumpeter [1911] 1982; Porter 1980, 1985; Ghemawat 1998) and political institutions (North 1990, 2005; Bates 2001; Grief 2006; Aligica and Boettke 2009). As noted, the formalist approach does not allow one to even begin to get purchase on most questions of this kind, though sometimes-as in Coleman (1990) and Glimcher (2012)-explicit implications for formal relationships are drawn from informal inductive reflection.

Once we get as far as asking whether it is worthwhile to explore pairwise relationships between economics and specific other disciplines, we can generalize this style of questioning to ask what, if anything, might be said about the place of economics in the overall architecture of systematic inquiry. There have been very few sustained investigations of this type. The investment required is considerable, as it demands broad and synaptic mastery of the history and philosophy of multiple fields of study; and the expected return is relatively meager, as even the minority of economists who find value in cross-disciplinary comparisons are often skeptical about the practical point of studies that necessarily cast their focus far from the empirical ground. Yet, for all that, the general question once raised is irresistible, even if only for late-night reflections with a glass of wine, to any economist who is self-conscious about her discipline's roots, limits, and future. And then such an economist might wish that some altruistic scholar would take on the burden of mounting a rigorous interrogation. In the person of Carsten Herrmann-Pillath, this selfless scholar has appeared.

I begin by outlining the structure and principal claims of HerrmannPillath's magnum opus. First, he identifies the general foundations of economics, along with the other behavioral and social sciences, in 
formal physical information theory. It is by reference to the principles and equations of this body of theory, he argues, that we should most fundamentally distinguish the sciences which traffic in evolutionary dynamics from others. Then he specifies the most general distinctive features of human evolutionary processes as being mediation by semiosis - that is, the gathering together of functionally related aspects of reality under signs, which in turn feed back to constrain and influence extra-symbolic behavior-and performativity-that is, the disposition to create causally effective structure by theorizing it. Semiosis and performativity enable uniquely human forms of niche construction, the term for organisms' modification of the environments that set the selection pressures for their development, thereby introducing feedback into their own evolution. Semiosis and performativity are first-order human forms of niche construction that make possible a powerful second-order form, technology, which is partly driven by semiotic and performative science, but which also, to at least as great an extent, follows an autonomous evolutionary pathway resulting from its dynamical impact on energetic stocks and flows. This contingent historical trajectory ultimately led the human species to experience an industrial revolution, which reached different communities at varying rates but now determines relevant adaptive niches for almost all humans. Industrialization in turn gave rise to accelerating specialization of labor, and to the wider special patterns of agency-norms of consumption, production, contracting, investment, incorporation, and so on-that characterize the making of and responses to markets. Markets then have their own general characteristics that distinguish them from other niches or other types of institutions, and naturally their semiotically empowered participants track those general characteristics by building a performative body of evolving theory-the activity they call 'economics'.

This summary sketches a carefully constructed and intellectually attractive edifice. Although the building turns out to have a few flawed features when examined in close detail, considered at wide resolution I believe it to be by far the most thorough and systematic account of the scientific context of the discipline of economics that anyone has yet produced.

Philosophers reading this far may wonder about the extent to which Hermann-Pillath, an economist specializing in Chinese business institutions, has taken the time and trouble to integrate his general 
intellectual structure with those developed by their tribe. I am pleased to report that philosophers not only have nothing to feel superior about in this instance, but have much to learn. The single greatest influence on Herrmann-Pillath appears to be C. S. Peirce, and the text indicates close knowledge of and careful reflection on the best contemporary Peirce scholarship. As Peirce is my own personally preferred candidate for greatest philosopher of all time, I admit to bias here. But I am confident that no one will be able to reasonably claim that the book is philosophically shallow. And it provides entry to a remarkable surprise, a resurrection of Hegel, of all people, as a farsighted anticipator of currently widespread views in the philosophy of social agency, whose work was open to misappropriation by mystics and romantics, and to widespread abuse for being so appropriated, because he lacked access to the pending conceptual innovations of Darwin, Peirce, and the early sociologists. With a co-author, Ivan Boldyrev, Herrmann-Pillath has given this striking idea its own book-length treatment (Herrmann-Pillath and Boldyrev 2014), so the proposal is far from casual. If the suggestion bears critical weight, then, given Hegel's never-disputed influence on Marx, important new lines of inquiry in the historical philosophy of economics may open up.

All this notwithstanding, few economists will be attracted to a long and difficult book about ontology and epistemology by an assurance that its author has paid his philosophical dues. As someone who has been thinking and writing for many years about relationships of the kind Herrmann-Pillath explores, I can conjecture how the typical economist may respond to my summary above of material that Hermann-Pillath spends 600 pages setting out. I expect that the following thoughts would cross her mind. First, she will struggle to imagine how Herrmann-Pillath's structuring of the disciplines and their core theories could speak meaningfully to her activities of problem selection, model specification and estimation, parameter and causal channel identification, and policy recommendation. She is likely to wonder what possible empirical tests might favor the structure I sketched over possible alternatives-particularly as she is not likely to be able to conceive, herself, of any specific such alternatives. The last reflection would itself be a barrier to her engagement with the account. The value of any theoretical perspective relies on critical dialectics, but the typical economist might find that she can respond to HerrmannPillath's book only as she might to a daring jazz performance that 
breaks rules she never knew existed and explores structures she cannot pick out of the din.

On the other hand, increasing numbers of economists, perhaps by now a majority of the profession, are sensitive to the importance of institutions and social structures in modeling and causally explaining economic outcomes (Coyle 2007). A philosopher of science can point out that this automatically implicates economists in the domains of neighboring social and behavioral sciences where questions of disciplinary relationships cannot be evaded by appeal to formalism because there is no generally acknowledged mapping from systems of axioms to institutional and social processes; there are at most a few partial frameworks (e.g., Schotter 1981). Standard modeling approaches in social and institutional economics begin with the usual individual agents, specified by attributed preferences and then additionally assigned beliefs about distributions of variables, including variables related to risk. These preferences and beliefs are then modified by contingent values of social and institutional state variables using parameterizations that are seldom derived from any deeper theory. The introduction of group identity considerations into microeconomic models by Akerlof and Kranton (2000) is one of many examples of the kind of approach I have in mind here. In my experience, few economists yet have much inkling (though see Wilcox 2008) that, from the perspective of near-consensus opinion in the philosophy of psychology, the ontological assumptions implicit in such models are bankrupt. Preferences and beliefs, according to numerous persuasive arguments mustered over the past two decades by such philosophers, are not latent internal states of individual people which are then subject to modification by outside influences. Preferences and beliefs are, rather, culturally evolved symbolic structures used by communities of people to relate one another's behavioral histories and dispositions to choice situations that are typically, though not always, interactive, but are always normatively characterized as problems. Put simply, preferences and beliefs are social constructs, certainly descriptive but also partly and essentially normative, that individuals use to predictively model both themselves and others. They are not, and do not admit of reduction to, internal psychological (let alone neurofunctional) states (Burge 1986; Dennett 1991; McClamrock 1995; Bogdan 1997, 2000, 2009, 2010; Hutto 2008; Zawidzki 2013). 
Ironically, this kind of externalism about the content of (particularly) preferences is in no tension with the most hallowed core of mainstream microeconomic theory, the revealed preference account that informed Samuelson's (1947) original axiomatic model of the consumer. But Samuelson did not try to combine his model of the individual consumer with his (many) models of market processes, even though the most famous early forms of those models appeared in the same book. The individual economic agent plays no role in any of the models presented in Samuelson's Foundations, and the classic theory of that agent that Samuelson develops to rationalize downward sloping demand was declared by him, in the concluding words of the chapter devoted to it, to be of little probable importance to economics (Ross 2014). However, as soon as economists who assumed individualistic ontologies of intentional states did try to put the Samuelsonian consumer to work-for example, in Milton Friedman's (1956) model of lifetime consumption smoothing, which Stigum (1990) pulls into his generalized formal economics-they faced a choice between combining revealed preference theory with an 'as if' story about the relationship between the model and real consumers, or projecting preferences and beliefs into people's heads as latent representations or dispositions. I do not think it overstates matters to say that what has resulted is an inconsistent muddle of mathematicized folk psychology and cognitivistic pseudo-science that has become an ever more serious methodological problem as economists have ventured deeper into domains they (confusingly) call 'behavioral'. This applies even to many macroeconomists, who lately find themselves contending with claims that business cycles result from social epidemics of pessimism and optimism (Akerlof and Shiller 2009). Such theory merely redescribes the phenomena it purports to explain because sound cognitive science will not vindicate the folk psychology on which it relies.

I thus think that a case can be made that a new philosophy of social agency in economic problem settings which can furnish a full-scale replacement for the atomistic cognitivism that economists collectively stumbled into between the 1950s and the 1980s should feature in the typical economist's demand schedule.

If I have persuaded any such economists, they should be warned that the book is hard sledding, and not merely because the themes it explores are difficult, deep and not yet embedded in familiar metaphors. The construction of many of its sentences is based on the syntactic logic 
of German rather than English. To pick one example: "[...] the most widespread definition of economics is actually misleading which relates scarce means to ends, because the essential question is how means and ends co-evolve" (p. 511). If you know how to render this into idiomatically identical German then you will not feel the Anglophone reader's instinctive need for a change in word order, a second comma, and a subordinate clause. Reading Herrmann-Pillath thus has much in common with reading translations of Hegel himself: the reader cannot expect to go through such sentences at normal reading speed, so the number of pages in the book understates its effective length.

However, most consumers of this book will be reading it as work and will, in principle, be getting paid for their time. So let them not whinge. I will use my remaining space here to emphasize the potential compensations for an economist who currently experiences moments of puzzlement about how her discipline folds into wider human knowledge. If such a reader thinks she would be a better economistnot to mention a better teacher of economics-to the extent that she was less puzzled about this, then the returns Hermann-Pillath has to offer are very great. In fact, no one has yet provided an account that better scratches the itch of the economist who feels adrift in the scientific firmament.

Here, then, are some of the notable product features from which you, the 'typical economist' I am idealizing, will get to benefit if you swallow the medicine.

First, the book's rigorous philosophical foundations in Peirce will expose the inadequacy of most existing stories about the supposedly philosophical 'foundations' of economics. Sciences do not, in general, need such foundations, regardless of how many philosophers say they do. But any account of the place of a science in the wider enterprise of human knowledge production is automatically a philosophy of the science in question. If you think that a bit of Popperian falsificationism will suffice where economics is concerned, then you really should read something more sophisticated or, for your own sake, foreswear ever discussing methodology in public. Herrmann-Pillath channeling Pierce will bring you all the way up to head table fitness in one volume.

Second, you will see why rejecting a formalist account of economics does not imply any reduction of its technical content. The economic domain is fundamentally statistical, and there is no such thing as formal statistics-but at the same time, there is no risk of running out of 
difficult novelties in econometric theory, so technophiles will remain as important as ever. A trend already well evident in the journals is that emphasis on mathematical elegance is steadily giving way to valorization of econometric know-how. Herrmann-Pillath's account will allow you to understand why this is not a mere change of fashion facilitated by faster computers and specialized econometrics software. It is, instead, what should be happening if the discipline is moving along the right track, because economics, like biology, is about information flow, and the science of information is part of the kingdom of statistics.

Third, you will learn how to stop relying on the silly 'as if' defense of attributing cognitive omniscience to economic agents in markets. You will be able to throw away this non-explanation of what you assume when you build models thanks to learning the doctrine of philosophical externalism about the mental. This is one of the very few ideas developed by philosophers more recent than Hume that you really should set out to grasp, because it explains how and why human behavior in market contexts conforms to a distinctive kind of orderliness that it largely lacks in other settings-one important economist who has emphasized this is Vernon Smith (2008). According to Herrmann-Pillath, Hegel deserves some of the credit for this idea. While struggling through Herrmann-Pillath, you can thus make yourself feel better by saying "this way I don't have to read Hegel". Perhaps, however, Herrmann-Pillath will inspire you to read some other first-order philosophy on this subject more accessible than Hegel; I recommend Zawidzki (2013). The 'as if' doctrine about agents' apparently miraculous information processing in market contexts is typically referred to as 'instrumentalism'. By reading Herrmann-Pillath's book you will come to understand its insightful conclusion that "[...] economic instrumentalism is a disguised form of sociological reasoning, because it factually adopts an externalist approach to rationality inappropriately cast into internalist language" (p. 211). When the disguise is removed, the motivation for instrumentalism vanishes. Economics as a discipline is much closer in both its assumptions and its explananda to sociology than to psychology (Ross 2014). It is mainly confused philosophy of mind that has obscured this fact, and that has simultaneously distorted economists' sense of where they should look for borrowings from the neighbors.

Fourth, you will see how to address the current conceptual chaos in social economics, where more or less complete anarchy governs usage 
of the notions of convention, norm and institution. Economists perhaps suspect that they are importing this anarchy from sociology and so are not responsible for it. Even if that were correct, which it is not, it would not mean that nothing should be done to create some order. HerrmannPillath provides a rigorous systematization of these three concepts and their relationships to one another. The systematization itself is derived from general philosophy of social science, and is then applied carefully to the domain of markets. For example, according to Herrmann-Pillath's typology, although all prices coordinate expectations, wages and interest rates in a modern economy are institutionalized, properly speaking, whereas the price of a slice of pizza in New York (in January 2014, $\$ 1$ around West 40th Street and 8th Avenue, $\$ 2.50$ four blocks south on 7th Avenue) is not. The difference is not that interest rates do not vary as much as pizza prices (they do); it is rather that the processes that control variation in the former are more transparent and less responsive. This should matter to you if you design structural models of price-generation. Herrmann-Pillath's systematization should be the basis for improved cross-comparability in such models, and can provide guidance to experimenters when they are deciding which laboratory variables to fix exogenously and which they should allow to arise endogenously.

Fifth, you will gain a new appreciation of how subtle, not to say slippery, is the distinction between production and consumption. Mainstream economists should not be so impressed with the logical and empirical gaffes in Marx's labor theory of value that they ignore his correct observation that consumption produces human capital. Most economists now recognize status as a form of social capital and the basis of network assets, so even luxury consumption has this productive aspect. Herrmann-Pillath elevates this tension between classical and neoclassical thought from the domain of ambiguous conceptual conventions to firm adjudication in the technical science of bioenergetic systems. That is, rigorous technical distinctions from a domain more general than economics are developed to do rigorous work that the intuitive distinction between production and consumption cannot. As Herrmann-Pillath explains, increasing labor productivity is the basic bootstrap for growth and technological progress. This is illustrated in terms economists will recognize by his account of what they call 'the Salter cycle' as a special case of more general hypercyclic dynamics (p. 470). Marx tried to ride this generic insight about 
production-consumption cycles too hard and too far, partly because in his hands it was little more than an intuition. Following a century and a half of developments in systems theory, applied in both biochemistry and thermodynamics, Herrmann-Pillath can correct Marx without introducing any extraneous ideological considerations, and in a way that, once again, builds bridges to mathematical developments in other sciences that can guide modeling in economics. Production and consumption are tightly related aspects of a single underlying dynamic of technological niche construction that gives rise to evolving market structures.

Sixth, and closely related to the fifth feature, you will learn how to think in a subtle and creative way about relationships between classical and neoclassical analyses. Comparative advantage, as Adam Smith taught, depends on specialization, but specialization as a real process is dynamic and depends on observations of relative price differences. These in turn can only be reliably identified when there are monetary institutions. Thus, according to Herrmann-Pillath, even though neoclassical utility concepts are crucial for representing preferences that range over risk and time, money remains a fundamental concept for microeconomists. Relatedly, the distinction between microeconomics and macroeconomics arises because global-scale markets can clear in the accounting sense (credit and debit columns, counted in money, balance) leading to global equilibrium (the aggregate credit balance plus wealth in hand = financed production) even though many individual markets are not clearing. Thus we arrive at a philosophical complement to the practical point, increasingly recognized by economists following the events of 2008 and beyond, that the strange activity of building macroeconomic models that do not specify and incorporate a financial sector cannot be soundly motivated by appealing to 'microfoundations'.

Seventh, as with consumption and production, you will learn how to view a range of economic concepts as empirically anchored in evolutionary dynamics. For example, 'scarcity' if it is to be a useful scientific concept, must designate more than the mere fact that a factor is not infinitely supplied at a marginal cost of zero. An economist who notices this obvious point might be inclined to seek an alternative operationalization. But, Hermann-Pillath explains, this would be a mistake based on confusion about the ontological nexus of the concept.

Scarcity is not an economic category but an evolutionary category [...] Scarcity is a short-hand notion for all selective pressures that 
operate on human behavior, also in the context of markets, but scarcity is also endogenous to evolutionary niche construction. Hence, scarcity is essentially related with novelty (p. 511).

The main point here, that scarcity is both relative and dynamic, is empirically persuasive. However, this also serves as an example of a style of reasoning that will likely strike most economists as peculiar, based on the highly questionable idea that disciplines are distinguished in part by being assigned custodianship of concepts.

Of course disciplines are historically and practically associated with specific concepts. However, Herrmann-Pillath is not as careful as I think he should be to avoid laying down a priori legislation about disciplinary limits, with all of the conservative implications of that philosophical attitude. For example, early in the book he mentions work, such as that collected in Noë, et al. (2001), which applies economics to the analysis of intraspecific and interspecific behavioral relationships among nonhuman animals and then announces that "I am not in favour of these extensions because they do not lead to a sustainable arrangement between the various scientific disciplines" (Herrmann-Pillath 2013, 53). Presumably Herrmann-Pillath does not mean that he wishes this empirical and modeling work were not done at all, but only that he prefers that it not be called 'economics'. His reason for this seems to be that non-human animals cannot signify themselves to themselves as such, nor (therefore) engage performatively to produce economics 'properly speaking'.

While appreciating the substantive point being made, I am not sympathetic to Herrmann-Pillath's following the lead of Kant in anointing disciplines with 'essential' missions that define rigid borders around them. It is fine to say that economists have been, historically, mainly interested in markets that are institutionally stabilized, and that this explains the nature of the boundaries that have actually been observed between economics and psychology on the one side, and between economics and sociology on the other side. I am also happy to add a normative dimension to this descriptive claim, and say, for example, that many behavioral economists have inappropriately ignored the first historical boundary and have consequently launched criticisms of other economists that amount to taking them to task for not being psychologists. However, both of these points of sympathy with Herrmann-Pillath are compatible with the view that boundaries between disciplines are fuzzy and often overlapping, and thereby generate 
productively disputable territory, and that they furthermore shift over time. To return to the example at hand, it does not trouble me at all to say that at coral reefs where fish queue up to have parasites removed by other fish who extract some 'payment' by also nipping off a few scales, we find non-human markets that are appropriately analyzed by economists even though the economics in question plays no performative role in the behavior of the participants.

Essentialism about performativity may also be related to what I regard as Herrmann-Pillath's excessively sweeping negative remarks about equilibrium analysis in economics. I agree with him (and Hayek, and many entirely mainstream contemporary economists) that it is never a true, or indeed sensible, thing to claim that a large economy is 'at' or 'approaching' general equilibrium (GE), which would be equivalent to saying that both excess demand and excess supply are zero and no one has any incentive to plan to do anything they are not already planning or to learn anything until there is an 'exogenous shock'. Herrmann-Pillath is of course aware that there are important equilibrium concepts other than GE, including Nash equilibrium (NE) and special-market-clearing equilibrium (Marshallian partial equilibrium or PE) that are important in economics. He explicitly agrees that PE often applies to specific markets-indeed, this is essential to his account of the micro/macro distinction, as we saw above. And he nowhere attacks, for example, the idea that oligopolistic suppliers (e.g., Coke and Pepsi) might settle into long-running NE. But even GE, understood as the solution concept for certain sets of closed-form equations defining convergent functions, can be a highly useful analytic tool for economists. If I am studying a national economy, I know that it is a heterogeneous bundle of stochastic data generating systems. Agreeing with Herrmann-Pillath's case against atomistic individualism about agents, I recognize that these bundles do not decompose into particular people, but I do not let this trouble me. I write down a few simple closed-form models of the responses of the economy to changes in a variable that interests me (presumably because someone has policy control over it). Then I estimate a maximum likelihood function that tells me which of my models best describes the responses of various types of data-generating bundles, which I idealize as 'sectors'. The result is a structural model of a lot of statistics about sector inputs and outputs. Now, the models I use in my mixture had each better have an equilibrium solution; otherwise I cannot decide what econometric model 
to use for estimation. And when, at the end, I predict the outcome for the economy of wiggling my variable of interest, the result is a representation of an equilibrium. Knowing that equilibrium never literally describes a real economy, I warn the policy-maker that all this means is that I predict that if she pushes the variable to such-and-such a value, the evolving economy will then pass through, or close to (with error quantified in my analysis) one of the states that in my model is represented as an equilibrium. The importance of this for policy recommendation and choice is that we know how to use equilibrium analysis to explore aggregate welfare comparisons. For an example of GE analysis in policy-focused economics of the kind I am imagining, and to which I can find no basis for objection in Herrmann-Pillath's book, consider Harrison et al (2002).

However, reflection on Herrmann-Pillath's general picture of economics as, fundamentally, the science of markets as a species of complex systems, and of the special form of agency to which markets give rise, can deepen the economist's value as a policy advisor beyond what technical analysis by itself achieves. Suppose that my advice to a policy-making client as imagined above leads her to decide to manipulate the variable I have focused on within the range I have suggested, but that she also asks me, "And then what happens?". If I have taken Herrmann-Pillath's account seriously I should not reply by saying that the economy will remain in its new equilibrium until, after a period I cannot specify, some or other exogenous shock, which by methodological definition I cannot describe, occurs. I will have to admit to the client that, after her intervention plays out, I will need to gather new measurements and model everything again. But if she is unhappy with this, because she wanted policy advice good for all time, I can explain to her that the error terms in both my base models and the output structural model assume various things to be uncorrelated, some of which are bound to become correlated, possibly quite rapidly. That is how things are with living dynamic systems, of which the inter-linked cluster of markets we call an 'economy' is a special kind.

The reader will notice-perhaps with satisfaction-that in the imagined story my client must pay me indefinitely to make new models and estimations regardless of whether I justify this by empty rhetoric about exogenous shocks or by offering a tutorial on the statistics of dynamical systems. But in the second instance she spends her resources on the basis of sound scientific explanation, whereas in the first 
instance she is put off with bluster. Philosophy can only ever matter to people who care about this distinction, and not every practical person does. But economists who so care should carve out time for HerrmannPillath's major contribution to the discipline's self-understanding.

\section{REFERENCES}

Ainslie, George. 1992. Picoeconomics. Cambridge: Cambridge University Press.

Ainslie, George. 2001. Breakdown of will. Cambridge: Cambridge University Press.

Akerlof, George, and Rachel Kranton. 2000. Economics and identity. Quarterly Journal of Economics, 115 (3): 715-753.

Akerlof, George, and Robert Shiller. 2009. Animal spirits. Princeton: Princeton University Press.

Aligica, Paul, and Peter Boettke. 2009. Challenging institutional analysis and development: the Bloomington school. London: Routledge.

Bates, Robert. 2001. Prosperity and violence. New York: Norton.

Bogdan, Radu. 1997. Interpreting minds. Cambridge (MA): MIT Press.

Bogdan, Radu. 2000. Minding minds. Cambridge (MA): MIT Press.

Bogdan, Radu. 2009. Predicative minds. Cambridge (MA): MIT Press.

Bogdan, Radu. 2010. Our own minds. Cambridge (MA): MIT Press.

Brynjolfsson, Erik, and Andrew McAfee. 2012. Race against the machine. Seattle: Digital Frontier Press.

Burge, Tyler. 1986. Individualism and psychology. Philosophical Review, 95 (1): 3-45.

Clark, Andy. 1997. Being there. Cambridge (MA): MIT Press.

Clark, Gregory. 2009. A farewell to alms. Princeton: Princeton University Press.

Coleman, James. 1990. Foundations of social theory. Cambridge (MA): Harvard University Press.

Coyle, Diane. 2007. The soulful science. Princeton: Princeton University Press.

Dennett, Daniel. 1991. Consciousness explained. Boston: Little Brown.

Friedman, Milton. 1956. A theory of the consumption function. Princeton: Princeton University Press.

Ghemawat, Pankaj. 1998. Games businesses play. Cambridge (MA): MIT Press.

Glimcher, Paul. 2012. Foundations of neuroeconomic analysis. Oxford: Oxford University Press.

Greif, Avner. 2006. Institutions and the path to the modern economy: lessons from medieval trade. Cambridge: Cambridge University Press.

Harrison, Glenn, Jesper Jensen, Morten Lau, and Thomas Rutherford. 2002. Policy reform without tears. In Policy evaluation with computable general equilibrium models, eds. Amedeo Fossati, and Wolfgang Wiegard. London: Routledge, 20-36.

Herrmann-Pillath, Carsten. 2013. Foundations of economic evolution. London: E. Elgar.

Herrmann-Pillath, Carsten, and Ivan Boldyrev. 2014. Hegel, institutions and economics: performing the social. London: Routledge.

Hutto, Dan. 2008. Folk psychological narratives. Cambridge (MA): MIT Press.

Kahneman, Daniel. 2011. Thinking fast and slow. New York: Farrar, Straus and Giroux.

Leamer, Edward. 2012. The craft of economics. Cambridge (MA): MIT Press.

Mas-Colell, Andreu, Michael Whinston, and Jerry Green. 1995. Microeconomic theory. Oxford: Oxford University Press. 
McClamrock, Ron. 1995. Existential cognition. Chicago: University of Chicago Press.

Noë, Ronald, Jan van Hoof, and Peter Hammerstein (eds.). 2001. Economics in nature. Cambridge: Cambridge University Press.

North, Douglass. 1990. Institutions, institutional change and economic performance. Cambridge: Cambridge University Press.

North, Douglass. 2005. Understanding the process of economic change. Princeton: Princeton University Press.

Ofek, Haim. 2001. Second nature. Cambridge: Cambridge University Press.

Porter, Michael. 1980. Competitive strategy. New York: Free Press.

Porter, Michael. 1985. Competitive advantage. New York: Free Press.

Ross, Don. 2005. Economic theory and cognitive science: microexplanation. Cambridge (MA): MIT Press.

Ross, Don. 2014. Philosophy of economics. Houndmills Basingstoke: Palgrave Macmillan.

Samuelson, Paul. 1947. Foundations of economic analysis. Cambridge (MA): Harvard University Press.

Schelling, Thomas. 1978. Egonomics, or the art of self-management. American Economic Review, 68 (2): 290-294.

Schelling, Thomas. 1980. The intimate contest for self-command. Public Interest, 60: 94-118. Schotter, Andrew. 1981. The economic theory of social institutions. Cambridge (UK): Cambridge University Press.

Schumpeter, Joseph. [1911] 1982. The theory of economic development. Piscatoway: Transaction.

Simon, Herbert. 1957. Models of man: social and rational. New York: Wiley.

Smith, Vernon. 2008. Rationality in economics. Cambridge: Cambridge University Press. Stigum, Bernt. 1990. Toward a formal science of economics. Cambridge (MA): MIT Press. Wilcox, Nathaniel. 2008. Against simplicity and cognitive individualism. Economics and Philosophy, 24 (3): 523-532.

Zawidzki, Tad. 2013. Mindshaping. Cambridge (MA): MIT Press.

Ziman, John (ed.). 2000. Technological innovation as an evolutionary process. Cambridge: Cambridge University Press.

Don Ross is professor of economics and dean of commerce at the University of Cape Town, and program director for methodology at the Centre for the Economic Analysis of Risk at Georgia State University. His areas of recent research include economic methodology; experimental economics of risk and time preferences in vulnerable populations; strategic foundations of human sociality; and scientific metaphysics. His many publications include Economic theory and cognitive science: microexplanation (2005), Every thing must go: metaphysics naturalized (with James Ladyman, 2007), Midbrain mutiny: the picoeconomics and neuroeconomics of disordered gambling (with Carla Sharp, Rudolph Vuchinich, and David Spurrett, 2008) and Philosophy of economics (2014). Contact e-mail: <don.ross931@gmail.com> 